Avrupa ve Kuzey

Amerika ülkelerindeki

diş hekimliği

fakültelerinde anatomi

eğitimine dair

karşılaştırmalı bir

inceleme

\section{An investigation on the anatomy \\ education at dental faculties in European and North American universities}

\section{Dt. Alican Pamay}

İstanbul Üniversitesi, Diş Hekimliği Fakültesi, Temel Tıp Bilimleri, Anatomi Bilim Dalı, İstanbul

Uzm. Dr. Mete Büyükertan

İstanbul Üniversitesi, Diş Hekimliği Fakültesi, Temel Tıp Bilimleri, Anatomi Bilim Dalı, İstanbul

Doç. Dr. Hüseyin Avni Balcıoğlu

İstanbul Üniversitesi, Diş Hekimliği Fakültesi,

Temel Tıp Bilimleri, Anatomi Bilim Dalı, İstanbul

Geliş Tarihi: 16 Mart 2017

Kabul Tarihi: 08 Nisan 2017

DOI: 10.5505/yeditepe.2017.44154

\author{
Yazışma Adresi: \\ Doçent. Dr. Hüseyin Avni Balcıoğlu \\ İstanbul Üniversitesi, Diş Hekimliği Fakültesi \\ Temel Tıp Bilimleri, Anatomi Bilim Dalı \\ 34340 i̇stanbul
}

Tel: 02124142424

E-posta: habalci@gmail.com
ÖZET:

Amaç: Eğitimi son birkaç yüzyıla kadar genel tıp eğitimi içinde olan diş hekimliği bilimleri, kurumsal ve yerleşik bir yapıyı genel tıp disiplinlerinin geleneğinden faydalanarak kurmuştur. Takip eden dönemlerde özel ve özgün bir tıbbi disiplin olarak diş hekimliği, teorik ve uygulama alanlarının bilimsel parametrelerini belirlemiş, alt dallarının yapılanmasını oluşturmuş ve bağımsız bilimsel çerçevesini inter/ multi disipliner bir düzlemde güncel tıp ve teknolojiye paralel olarak bilimsel dolaşımdaki yerini genişletmiştir. Temel tıp bilimlerin ve primer tıbbi uygulamaların yanı sıra, ağırlıklı olarak, ağız içi tedavi ve ağız cerrahisi, diş hekimliği bilimlerinin müfredatının sınırlarını çizer.

Gereç ve yöntem: Bu makalede, teknolojide olduğu gibi eğitimde de öncü olan Kuzey Amerika ve Avrupa ülkelerindeki diş hekimliği fakültelerindeki anatomi eğitiminin ülkemizle de karşılaştırılarak analizinin yapılması amacıyla söz konusu ülkelerdeki anatomi bölümlerine, içeriğinde her bir bölümün yapılanmasından, ders saatlerine değin, ilgili fakültedeki anatomi eğitim ve öğretiminin detaylarının cevaplanacağı soruları içeren bir anket e-posta ile gönderildi.

Bulgular: Gelen cevapların değerlendirmesiyle birlikte anatomi eğitiminin genel bir eğitim öğretim değerlendirilmesi yapıldı.

Sonuç: Sonuç olarak, kendi dinamiklerimizle, kendi eğitim-öğretim birikimimizle ve yetişmiş eğitim-öğretim kadromuzla belirlenecek ancak bu örneklerin ışığında geliştirilecek bir model, Türk diş hekimliği fakültelerindeki eğitim için ideal müfredatı oluşturabilir.

Anahtar kelimeler: Diş hekimliği eğitimi, anatomik bilimler, müfredat

\section{SUMMARY}

Aim: As one of the core disciplines of medicine, dental education is built on long lasting tradition of medical science. Therefore, curriculums of many dentistry schools in the world contain similarities with each other. Courses covering fundamentals of medicine and primary medical applications, as well as dental surgery and dental treatments are main cornerstones of dental programs. On top of that, despite some minor differences, core anatomy courses are identical in terms of content, curriculum and applications for dental and medicine disciplines. As one of the minor differences mentioned before, dental schools have to prioritize head and neck anatomy in comparison with medical schools.

Materials and Methods: This study questions the topic for dental schools in Europe and North America compared to schools in Turkey. For this purpose, a survey is prepared to evaluate dental programs in terms of organizational structure in the department, contents for available courses at the faculty and shared with dental schools in the world.

Results: A study is conducted to summarize the results of the survey. 
Conclusions: As a conclusion, an ideal curriculum for dental faculties in Turkey should be based on its own background, experiences and created by its own academic staff.

Key words: Dental education, anatomical sciences, curriculum.

\section{GíRiş}

Yüksek öğretimde ders yapılanması, farklı ülkelerde, o ülkelerin farklı şehirlerinde, hatta o şehirlerin de farklı fakültelerinde, daha çok da çeşitli ekollere paralel olarak belirli öğretim yöntemlerini benimsemiş okullarda değişiklikler gösterir. Müfredat, bu değişikliklerin varlığında, fakültenin ya da bağlı olduğu üniversitenin temel eğitim prensipleri düzleminde, gelecek projeksiyonu olan, öğrenciye aktarılan bilginin pratik karşılığının varsayıldığı sistematik bir kılavuz önerir. İdeal ders sayısı ve saatinin belirlendiği ve zaman-mekan olanaklarının doğru, hedefe dönük olarak planlandığı bir çerçeve sunması gereken müfredat, alanın yetkin öğreticileri tarafından ortaya konur.

Literatürde diş hekimliğinde anatomi eğitimi ile ilgili yayınlanmış çeşitli araştırmalar, değerlendirmeler ve yorumlar bulunmaktadır. ${ }^{1-7} \mathrm{Bu}$ çalışmalar konunun daha çok tartışılarak bilimsel bir eksende anatomi eğitiminin ileriye götürülmesine yardımcı olmaktadır. Araştırmalar, diseksiyon temelli anatomi eğitimi anlayışının son yıllarda yerini proseksiyona ve bilgisayar tabanlı modellemeye bırakmaya olan eğilimini ortaya koymaktadır. ${ }^{5}$ Modern teknolojik donanımların diş hekimliği pratiğinde rutin kullanım alanları bulması ve diş hekimliği prosedürlerinin genişlemesiyle beraber; radyolojik anatomi, klinik anatomi gibi disiplinlerin öne çıkması, klasik anatomi eğitiminde progresif değişiklikleri kaçınılmaz kılmaktadır. ${ }^{1,7}$ Bu gelişmeler, diş hekimliğinde anatomi eğitimi verenleri daha iyi bir ders içeriği ve aktarım yöntemleri konusunda araştırmalara yönlendirmiştir. Diş hekimliğinde temel anatomi pratik eğitiminin anatomi laboratuvarlarında akran eğitmenler tarafından verilmesinin öğrenciler ve öğrenim açısından getirilerinin değerlendirilmesinden, diş hekimliği bilgisayar destekli laboratuvar eğitimi ve geleneksel laboratuvar eğitiminin karşılaştırmalı analizine dayanan araştırmalara kadar farklı düzlemlerde çalışmalar yapılmıştır. 2, 8,9

ADA (American Dental Association) yaptığı anket çalışmalarıyla ülke çapında Akredite Eğitim Programı'nı değerlendirmiş ve sonuçları yayınlamıştır. Bu değerlendirme diş hekimliği fakültelerindeki anatomi eğitimi ile ilgili ayrıntılı bilgiyi vermektedir. ${ }^{10}$ Dünyanın geri kalan ülkelerinde ve ülkemizde yapılmış bu türden bir çalışma bulunmamaktadır. Bu çalışmanın amacı, Avrupa ve Kuzey Amerika Ülkelerindeki Diş hekimliği fakültelerinde anatomi eğitimine dair bir kesit sunarken ülkemizdeki durumla ilgili olarak da karşılaştırmalı bir analiz ortaya koymaktır.

\section{GEREÇ VE YÖNTEM}

Kuzey Amerika ve Avrupa ülkeleri diş hekimliği fakültelerindeki anatomi eğitiminin güncel durumunun araştırıması amacına uygun olarak, söz konusu ülkelerdeki anatomi eğitim-öğretim programlarının detaylarına ulaşılmaya çalışıldı, konu ile ilgili literatür incelendi. Alt bölümleri de olan, 6 adet sorudan oluşan kısa bir anket hazırlanarak, bir web sitesine yönlendirildi. Kuzey Amerika ve Avrupa ülkelerindeki diş hekimliği fakültelerinin ilgili birimlerine kısa bir açıklayıcı metni ve bu web sitesinin linkini içeren e-postalar gönderilerek anket formunun doldurulması istendi. Anketi dolduracak kişilerin en az düzeyde vakitlerini alacak şekilde düzenlenen anket çoktan seçmeli cevap seçenekleri içermekteydi. Anketler üzerinden gelen cevapların sayısına göre, fakültelerin web adreslerinde daha detayları incelemeler yapıldı.

\section{BULGULAR}

Anket kapsamında cevaplanması istenen ilk soru olan, ilgili diş hekimliği fakültesinde bir anatomi bölümünün olup olmadığı sorusuna, ankete katılan 16 Kuzey Amerika diş hekimliği fakültesinden $6^{\prime}$ SI $(\% 37,5)$ evet, geri kalan $10^{\prime} u(\% 62,5)$ hayır cevabı verdi. 64 Avrupa diş hekimliği fakültesinden $44^{\prime}$ ü $(\% 68,75)$ evet, geri kalan 20 'si

$(\% 31,25)$ hayır cevabı verdi.

Anketin ilk sorusuna evet cevabını veren okullardan ikinci soruyu, hayır cevabını verenlerden ise üçüncü soruyu cevaplamaları istendi. Ancak sonuçlara göre; bu duruma uymayan ve her iki soruya da yanıt veren okulların olduğu görülmüştür.

İkinci sorunun ilk kısmında bünyelerinde müesses bir anatomi bölümü olan fakültelerin mevcut öğretim elemanı sayısı soruldu.

Soruya cevap veren 12 Kuzey Amerika okulundan $5^{\prime} i$

(\% 41,67) 4'ten az, 3'ü (\%25) 4, 3'ü (\%25) 5, $1^{\prime}$ i i ise $(\% 8,33)$ $5^{\prime}$ ten fazla cevabını vermiştir. Soruya cevap veren 49 Avrupa okulundan 33'ü $(\% 26,53) 4^{\prime}$ ten az, 4'ü $(\% 8,16) 4$, 8 'i $(\% 16,33) 5$, $4^{\prime} u ̈$ ise $(\% 48,98) 5^{\prime}$ ten fazla cevabını vermiştir.

İkinci sorunun ikinci kısmında ise anatomi bölümü olan fakültelerdeki eğitim görevlilerinden kaçının diş hekimi kökenli anatomist olduğu soruldu. ${ }^{7}$ Kuzey Amerika diş hekimliği fakültesinin ikisinde diş hekimi kökenli anatomist bulunmazken ikisinde 1 ve ikisinde 2 ve birinde dört adet diş hekimi anatomist bulunmaktaydı. 31 adet Avrupa ülkesinde ise 9 okulda diş hekimi anatomist bulunmazken, 6 okulda 1, 4 okulda iki, üç okulda 3, üç okulda 4, üç okulda 5, bir okulda 6, bir okulda 7 diş hekimliği kökenli anatomist bulunduğu belirlendi.

Üçüncü soruda, bünyelerinde anatomi bölümü olmayan fakültelerde anatomi eğitiminin kim tarafından verildiği 
soruldu. Illk soruya hayır cevabını veren ve ikinci soruyu geçen ya da hem ikinci hem de üçüncü soruya cevap veren diş hekimliği fakülteleri, eğitimin tıp fakültelerinde verildiğini ya da anatomi öğretim elemanlarının tıp fakültelerinden geldiğini belirten cevaplar verdiler. Bu soruda çoktan seçmeli yerine yazılı cevap istenilmesi sebebiyle fakülteler tarafından verilen cevaplar genellikle aynı durumu ifade etseler de, ifade şekilleri çeşitlilik göstermekteydi.

Dördüncü soruda fakültelerden, öğrencilerin eğitim gördükleri anatomi laboratuvarlarında yararlanılan birincil eğitim metotlarının neler oldukları soruldu. Yanıtların çoktan seçmeli seçenekler arasından verilmesi istendi. Seçenekler arasında olmayan bir metot var ise bunun da "diğer" adı altında sunulan cevap bölümünde yazılı olarak belirtilmesi istendi.

Ankete katılan 16 Kuzey Amerika diş hekimliği fakültesinin $15^{\prime} i(\% 93,75)$ insan kadavrası, 2'si $(\% 12,50)$ disseke insan modelleri, $5^{\prime} i(\% 31,25)$ plastik anatomik modeller, 3'ü $(\% 18,75)$ yüzeysel anatomi, 7 'si $(\% 43,75)$ radyolojik anatomi seçeneklerini işaretleyerek, fakülte bünyesinde bu eğitim metotlarının mevcut olduğunu belirttiler.

Bu soruya yanıt veren 64 Avrupa diş hekimliği fakültesinin 40'ו ו (\%2,50) insan kadavrası, 34'ü $(\% 53,13)$ disseke edilmiş insan modelleri, 33'ü $(\% 51,56)$ plastik anatomik modeller, 17'si $(\% 26,56)$ yüzeysel anatomi, 15'i $(\% 23,44)$ radyolojik anatomi seçeneklerini işaretledi.

Beşinci soruda fakültelerde eğitim gören öğrencilerin gross anatomi laboratuvarlarında geçirdikleri sürenin haftada kaç saat olduğu sorusu sorularak cevaplar istenmiştir. 16 Kuzey Amerika üniversitesinden 1'i $1(\% 6,25)$, 2'si 3 (\%12,50), 3'ü 4 (\%18,75), 10'u 4 (\%62,50) saatten fazla seçeneğini işaretlerken, 2 saat seçeneğini işaretleyen üniversite olmadığı gözlenmiştir. 64 Avrupa üniversitesinden 5'i 1 (\%7,81), 16'sı 2 (\%25), 10'u 3 (\%15,63), 11'i 4 $(\% 17,19), 22$ 'si 4 (\% 34,38) saatten fazla seçeneğini işaretledi.

Anketin son sorusu olarak yöneltilen sorunun ilk kısmında fakültelere, gross anatomi eğitimin kaç dönem boyunca verildiği soruldu.

16 Kuzey Amerika üniversitesinden 10'u 1 (\% 62,50), 3'ü 2 (\%18,75), 2'si $3(\% 12,50), 1^{\prime}$ i 4 (\%6,25) dönem eğitim verildiğini belirtirken, 5 dönem seçeneğini hiç bir fakülte işaretlemedi.

Yanıt veren 64 Avrupa üniversitesinden 12'si 1 (\%18,75), $39^{\prime}$ u 2 (\%60,94), 8'i 3 (\%12,50), 4'ü 4 (\%6,25), 1'i 5 (\%1,56) dönem eğitim verildiğini belirtti.

Sorunun ikinci kısmında ise fakültelerden toplam kurs saatinin yazılı olarak belirtilmesi istenmiştir. Hem Avrupa hem de Kuzey Amerika ülkelerinin diş hekimliği fakültelerinde verilen anatomi dersi toplam saatinin çok büyük değişiklik gösterdiği bu araştırmanın önemli sonuçlarından biri olarak tespit edildi. Buna göre ankete cevap veren fakültelerdeki anatomi toplam ders saati 20 ile 245 saat arasında değişmekteydi.

\section{TARTIŞMA}

Ülkemizde, eğitim kurumları, güçlü bir eğitim-öğretim geleneğine sahip olmakla beraber, çeşitli tarihsel dönemeçlerle bu geleneğin zaman zaman kesintiye uğradığı görülmektedir. Türkiye Cumhuriyetinin ilk diş hekimliği fakültesi olan İstanbul Üniversitesi Diş hekimliği Fakültesi, 'İstanbul Diş Hekimliği Okulu' adı ile 1908 yılında kurulmuştur. 9 Kasım 1909 tarihli ilk ders programında 7 başıkta verilen dersler şunlardır: Diş Hastalıkları ve Kliniği, Diş Tedavisi Teoriği ve Pratiği, Fizyoloji, Histoloji, Anestezi, Diş hekimliği Farmakolojisi, Sağlık Koruma ve Anatomi'dir.

1970 tarihinde Diş hekimliği Fakültesi'nde Anatomi, Fizyoloji, Toplum Ağız Diş Sağlığı, Biyokimya, Histoloji ve Embriyoloji, Farmakoloji, Mikrobiyoloji ve Patoloji kürsüleri kurulmuştur. Her kürsüye ileride öğretim üyesi olarak yetiştirilmek üzere çoğu diş hekimi kökenli olan asistanlar alınmıştır.

ADA (American Dental Association) yaptığı anket çalışmalarıyla ülke çapında Akredite Eğitim Programı́nı değerlendirmiş ve sonuçları yayınlamıştır. Akademik programların, kayıt ve mezuniyet sonuçlarının baz alındığı bu çalışmadaki sonuçlar ADA'nın yaptığı "Survey of Dental Education (Diş Hekimliği Eğitimi Anketi) 2010-2011" vasıtasıyla toplanmıştır. Aynı zamanda eğitim giderleri ve mali yardım, hasta bakımı, gelişmiş diş eğitim ve öğretim pozisyonları gibi konular hakkında da bilgi toplanması amaçlanmıştır. Amerika'da bulunan 59 ve de Kanada'da bulunan 10 diş hekimliği fakültesine bu anket gönderilerek, doldurmaları talep edilmiştir. Çalışma içerisinde, 'Survey of Dental Education (Diş Hekimliği Eğitimi Anketi) 2010-2011' ile elde edilen bilgilerin yanında diğer bazı anketlerden elde edilen bilgilere de yer verilmiştir. Diş hekimliği fakültelerine yapılan başvuru verileri The American Dental Education Association (Amerikan Diş Hekimleri Eğitim Derneği) (ADEA) tarafından sağlanmıştır.

Amerika'nın 10 yılı kapsayan bu süreçte diş hekimliği eğitimi veren özel üniversite sayısının sabit kalıp, devlet üniversitesi ve özel-devlet üniversitesi sayılarının da 1'er adet artması, Türkiye'deki diş hekimliği eğitimi veren okulların son 10 yıl içerisindeki mevcut durumuyla ne denli bir fark oluşturduğunu da gözler önüne sermektedir.

Ülkemizdeki diş hekimliği eğitimi veren devlet üniversitelerinin sayısıyla paralel olarak vakıf üniversitelerin sayısı hızla artmaktadır. Amerika'daki diş hekimliği eğitimi veren özel üniversite sayısı 10 senelik zaman diliminde 1 adet artarken, Türkiye'deki sayı, 2009 yılından sonraki sadece 4 senelik süreçte 5 adet yani $\% 100$ oranında bir 
artış göstermiştir. Benzer durum Avrupa'daki diş hekimliği fakültelerinin sayısı açısından da gözlenmektedir.

Bu verileri daha spesifik hale getirip, araştırmamızın konusu olan ABD'ndeki diş hekimliği fakültelerindeki anatomi eğitimi ders saatleri incelendiğinde çok ciddi farklılıkların izlenebildiği bir tabloyla karşı karşıya kalınmaktadır. Gross Anatomy ve Nöroanatomi olarak iki ana alanda şekillenen anatomi müfredatı teorik ve pratik derslerin yapılanmasıyla ilgili olarak farklı fakültelerde farklı resimler vermektedir.

Bu çalışmadaki verilere göre; gros anatomi üzerine verilen teorik derslerin sene boyunca toplam saat değerleri ortalamasının 76, pratik ders sayısı ortalamasının ise 100 olduğu ortaya çıkmıştır. Ortalama değerlerden görüldüğü üzere; pratik ders saati ortalama değerinin, teorik ders saati ortalama değerinden belirgin bir şekilde fazla olması, ABD'nde diş hekimliği müfredatında anatomi dersi pratik uygulamalarına teorik uygulamalardan daha fazla önem atfedildiği görülmektedir.

Listeye baktığımızda verilen teorik ve pratik derslerin toplamında 80 saat ile 420 saat; teorik derslerin toplamında 29 saat ile 307 saat; pratik derslerine toplamında 31 saat ile 245 saat arasında değişen geniş bir yelpaze göze çarpmaktadır.

Nöroanatomi ders saatlerine bakıldığında teorik olarak 27 , pratik olarak 10 saatlik ortalama değerler görmekteyiz. 20 ye yakın sayıdaki üniversitede nöroanatomi pratik dersi verilmemektedir. Teorik ders sayısına baktığımızda 6 ile 68 saat arası değişen bir yelpaze görülmektedir.

Kuzey Amerika diş hekimliği fakültelerindeki anatomi eğitimini, yaptığımız araştırmanın ana unsuru olan anketimize katılan okullar ve cevapları üzerinden yorumlandığında birçok sonuca ulaşmak mümkündür.

Anketin ilk sorusu olan "Fakültenizde bir anatomi bölümü mevcut mu?" sorusuna verilen cevaplara göre anatomi bölümü olmayan fakültelerin daha ağırlıklı $(\% 68,75)$ olduğunu görmekteyiz. Bu fakültelerde eğitimin kimler tarafından verildiğini sorduğumuz üçüncü sorudaki yanıtlara göre belli başlı 3 temel ortak yanıt göze çarpmaktadır. Bunlardan ilki fakülte bünyesinde bulunan 'oral biyoloji' bölümünde bulunan anatomi hocaları tarafından verildiği, ikincisi tıp fakültesindeki ilgili birimden gelen hocalar tarafından diş hekimliği fakültesi bünyesinde eğitim görüldüğü iken üçüncüsü ise diş hekimliği fakültesindeki öğrencilerin anatomi eğitimi için tıp fakültesiyle ortak olarak hazırlanan kurs programı kapsamında tıp fakültesi binasında eğitim gördüğü cevaplarıydı.

Öte yandan tüm bunlarla birlikte bünyesinde anatomi birimi mevcut olan fakültelerin oranının da $(\% 37,50)$ pek azımsanmayacak bir değerde olduğu görülmektedir. Bu fakültelerdeki anatomi bölümünde görevli olan öğretim görevlerinin sayısını sorduğumuz ikinci sorunun ilk kısmında çoğunluk $(\% 41,67)$ 4'ten az yanıtını vermiştir. Bunlardan kaçının diş hekimi olduğunun cevabını aradığımız ikinci kısımda ise ilk kısma cevap veren okullardan çoğunun bu kısma cevap vermemesinden dolayı yorumlayabileceğimiz kayda değer bir veriye sahip olamamaktayız.

Fakültelere anatomi laboratuvarlarındaki birincil öğretim metotlarını sorduğumuz dördüncü soruda sunulan seçenekler arasında en çok işaretlenen $(\% 93,75)$ seçenek insan kadavrasıdır. Bundan yola çıkarak neredeyse fakültelerin tamamına yakınında anatomi eğitiminde insan kadavrasının kullanıldığını söyleyebiliriz. Proseksiyon $(\% 12,50)$ ve yüzeysel anatominin $(\% 18,75)$ ise başlıca eğitim metodu olarak benimsenmediği görülmektedir.

Fakültelerdeki öğrencilerin anatomi laboratuvarlarında haftada kaç saat geçirdiklerine dair beşinci soruya verilen cevaplardan en yüksek oranda $(\% 62,50)$ işaretlenen ' 4 'ten fazla' seçeneğiydi. Oranın bu denli yüksek olması tartışmanın önceki kısımlarında da bahsettiğimiz gibi, Amerika'da anatomi pratiğine ne denli önem verildiğini gözler önüne sermektedir. En çok işaretlenen ikinci seçeneğin, \%18,75 oranı ile ' 4 saat' seçeneği olması da önermemizi destekler niteliktedir.

Son soru olarak yönelttiğimiz 'Anatomi eğitimi kaç dönem verilmektedir?' sorusuna yanıt olarak en yoğun $(\% 61,50)$ verilen cevap ' 1 ' seçeneğidir. Üzerinde çok fazla yorum yapabilmemizin mümkün olmadığı bu veriye dayanarak ancak Kuzey Amerika'daki diş hekimliği fakültelerinde verilen anatomi eğitiminin, ders sayısı ve eğitim kalitesi alanında tek dönem olarak yeterli nitelikte olduğu düşüncesinin yaygın olduğunu söyleyebiliriz.

Ankete Avrupa'daki diş hekimliği fakültelerinin verdiği cevapları baz alarak yaklaşacak olursak karşımıza çıkan tablo şu şekilde olmaktadır:

Ülkemizde tüm bilim dallarının müesses olduğu temel tıp bilimleri bölümü yalnızca İstanbul Üniversitesi Diş Hekimliği Fakültesi'nde bulunmaktadır. Bunun dışında Marmara Üniversitesi Diş Hekimliği Fakültesi'nde de temel tıp bölümleri olmasına rağmen anatomi kürsüsü bulunmamaktadır. Ankara Üniversitesi Diş Hekimliği Fakültesi'nde anatomi bilim dalı vardır. Ancak diğer bilim dallarından bir kısmı eksiktir. Bunun dışında bir de Kırıkkale Diş Hekimliği Fakültesi'nde sadece anatomi bilim dalı bulunmaktadır.

Diş hekimliği fakültelerinde temel tıp bilimleri eğitimi çok önemli olduğundan, bu konudaki eksiklik diş hekimliği eğitimi açısından en önemli zafiyet göstergesidir. Her diş hekimliği fakültesinde fakülteye ait ve her temel tıp bilim dalının olduğu bir temel tıp bölümleri olması gereklidir. Okullara bünyelerinde bulunan söz gelimi anatomi kürsüsünde kaç tane öğretim görevlisi olduğu sorusunun yöneltildiği ikinci sorunun ilk kısmında neredeyse fakültelerden yarısı $(\% 48,98)$ " 5 ten fazla" yanıtını vermiştir. Bu 
durum da aynı önceki soruda olduğu gibi Kuzey Amerika ile aynı oranda zıtlık göstermektedir.

Bünyelerinde anatomi kürsüsü bulunmayan diş hekimliği fakültelerinden cevaplamalarını istediğimiz üçüncü soruda gelen yazılı cevaplar incelendiğinde, Kuzey Amerika okulları tarafından verilen cevaplara benzer bir şekilde cevapları kabaca 3 grup halinde detaylandırabiliriz. Buna göre, Avrupa genelindeki diş hekimliği fakültelerinde anatomi dersleri fakülte içinde bulunan 'oral biology' bölümünde görevli hocalar tarafından, tıp fakültesindeki anatomi bölümünden gelen eğitmenler tarafından ve de ilk sorunun verilerini değerlendirirken bahsedildiği üzere diş hekimliğinin tıp fakültelerinde alt bölüm olduğu ülkelerde bulunan okullardaki anatomi eğitmenleri tarafından verilmektedir.

Öğrencilerin haftada kaç saat pratik anatomi eğitimi aldıklarına dair cevap aradığımız altıncı soruda büyük çoğunluğun $(\% 34,38)$ 4'ten fazla cevabını verdiğini görmekteyiz. Ancak bu oranın diğer seçeneklere göre fazla bir üstünlük sağlamamaktadır.

Avrupa'daki diş hekimliği fakültelerinde teorik anatomi eğitiminin kaç eğitim dönemi boyunca verildiğini sorduğumuz son sorunun cevabı olarak açık ara en fazla verilen yanıtın $(\% 60,94) 2$ seçeneği olduğu göze çarpmaktadır.

İstanbul Üniversitesi Diş Hekimliği Fakültesi bünyesinde anatomi eğitimi, bu fakülteden mezun olan anatomi uzmanı diş hekimi eğitim görevlileri tarafından verilmektedir. Arzu edilen ideal durum bu iken Türkiye'deki diğer diş hekimliği fakülteleri genelinde ise tıp fakültelerinden gelen görevli hocalar tarafından eğitim verilmesi durumu mevcuttur.

Balcıoğlu ve ark. ${ }^{1}$ diş hekimliğinde anatomi eğitiminin gelecek perspektiflerine dair değerlendirmelerinde, temel bilimlerin klinik içeriğe entegrasyonu ile ilgili devam eden tartışmalar bahsinde bazı çatışmalı makaleleri de örnek göstererek, tam olarak nasıl ve ne öğretilmesi gerektiği konusunun önemli bir sorun olarak eğitim felsefesi tartışmalarında yerini aldığını belirtmektedir.

Dolayısıyla bir müfredat birliğinden söz etmek mümkün gözükmemekle birlikte bu raporların incelenmesiyle elde edilecek bir ideal müfredat örneğinden de bahsetmek söz konusu değildir. Demek ki; kendi dinamiklerimizle, kendi eğitim-öğretim birikimimizle ve yetişmiş eğitim-öğretim kadromuzla belirlenecek ancak bu örneklerin ışığında geliştirilecek bir model Türk diş hekimliği fakültelerindeki anatomi eğitimi için ideal müfredatı oluşturabilir.

Sonuç olarak, bu çalışma, dünyanın önemli ülkelerindeki diş hekimliği anatomi eğitiminin resmedilmesini hedeflemiştir. Diş hekimliği eğitiminde özel ve önemli bir yeri olan anatomik bilimlerin dünya standartlarına ulaştıııması, hızla gelişen ve dünya liderliğine doğru yol alan ülkemizin sağlık politikalarında yerini alması gereken önemli unsurlardan olmalıdır.

\section{KAYNAKLAR}

1. Balcıoglu HA, Kokten G, Guven Y. Future Perspectives of Anatomy in Dental Education: Quo Vadis? Int J Morphol. 2010; 28: 71-73.

2. Brueckner JK, Mac-Pherson BR, Benefits from peer teaching in the dental gross anatomy laboratory. Eur $\mathrm{J}$ Dent Educ 2004; 8: 72-77.

3. Gutmann GD, Ma TP, Mac-Pherson BR. Making Gross Anatomy Relevant to Dental Students. J Dent Educ 2003; 67: 355-358.

4. Lazarius MD, Chınchıllı VM, Leong SL, Kauffman GL Jr. Perceptions of anatomy: Critical components in the clinical setting. Anatomical sciences education 2012; 5: 187-199.

5. Redwood C J, Towsent GC, The Dead Center of the Dental Curriculum: Changing Attitudes of Dental Students During Dissection. J Dent Educ 2011; 75: 13331344.

6. Silverstein ST, Kritz-Silverstein D. A longitudinal study of stress in first-year dental students. J of Dent Educ 2012; 74: 1195-1199.

7. Vuchkova J, Maybury T, Farah SC, The Educational Value of Online Mastery Quizzes in a Human Anatomy Course for Digital interactive learning of oral radiographic anatomy. Eur J Dent Educ 2012; 16: e79-e87.

8. Bogacki RE, Best A, Abbey LM, Equivalence study of a dental anatomy computer-assisted learning program $\mathrm{J}$ Dent Educ. 2004; 68: 867-871.

9. Nance ET, Lanning SK, Gunsolley JC. Dental anatomy carving computer-assisted instruction program: an assessment of student performance and perceptions. J Dent Educ 2009; 73: 972-979.

10. American Dental Association resmi web sitesi http:// www.ada.org/. 